\title{
Lipoxin $A_{4}$ decreases human memory $B$ cell antibody production via an ALX/FPR2-dependent mechanism: A link between resolution signals and adaptive immunity
}

\author{
Sesquile Ramon ${ }^{*}$, Simona Bancos ${ }^{+}$, Charles N. Serhan ${ }^{ \pm}$, and Richard P. Phipps ${ }^{\star},+\S$ \\ "Department of Microbiology and Immunology, University of Rochester School of Medicine and \\ Dentistry, Rochester, NY 14642 \\ +Department of Environmental Medicine, University of Rochester School of Medicine and \\ Dentistry, Rochester, NY 14642 \\ ¿Department of Anesthesiology, Brigham and Women's Hospital, Harvard Medical School, \\ Boston, MA 02115
}

\begin{abstract}
Summary-Specialized proresolving mediators (SPMs) are endogenous bioactive lipid molecules that play a fundamental role in the regulation of inflammation and its resolution. SPMs are classified into lipoxins, resolvins, protectins and maresins. Lipoxins and other SPMs have been identified in important immunological tissues including bone marrow, spleen and blood. Lipoxins regulate functions of the innate immune system including the promotion of monocyte recruitment and increase macrophage phagocytosis of apoptotic neutrophils. A major knowledge gap is whether lipoxins influence adaptive immune cells. Here, we analyzed the actions of lipoxin $\mathrm{A}_{4}$ $\left(\mathrm{LXA}_{4}\right)$ and its receptor ALX/FPR2 on human B cells. $\mathrm{LXA}_{4}$ decreased IgM and IgG production on activated $B$ cells through ALX/FPR2-dependent signaling, which downregulated NF- $\kappa B$ p65 nuclear translocation. $\mathrm{LXA}_{4}$ also inhibited human memory $\mathrm{B}$ cell antibody production and proliferation, but not naïve $\mathrm{B}$ cell function. Lastly, $\mathrm{LXA}_{4}$ decreased antigen-specific antibody production in vivo. To our knowledge, this is the first description of the actions of lipoxins on human B cells, which shows a link between resolution signals and adaptive immunity. Regulating antibody production is crucial to prevent unwanted inflammation. Harnessing the ability of lipoxins to decrease memory B cell antibody production can be beneficial to threat inflammatory and autoimmune disorders.
\end{abstract}

\section{Keywords}

Human; B cells; antibodies; lipoxin

\section{Introduction}

Inflammation is a tightly regulated process triggered by the presence of foreign pathogens, trauma or injury. Foremost, resolving inflammation is vital to maintain homeostasis and to prevent chronic inflammation and disease. Lipid-derived specialized proresolving mediators

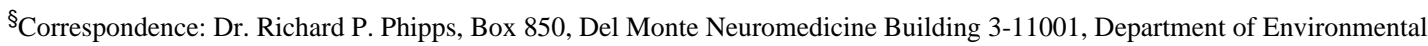
Medicine, University of Rochester School of Medicine and Dentistry, 601 Elmwood Avenue, Rochester, NY 14642, USA, Fax: +1-585-276-0239, richard_phipps@urmc.rochester.edu.

Disclosures

CNS is an inventor on patents on lipoxins and aspirin-triggered lipoxins and their stable analogs assigned to Brigham and Women's Hospital.
} 
(SPMs) have been identified as major players involved in the regulation of inflammation and its resolution [1, 2]. The identification of agonists of resolution demonstrated that resolution of acute inflammation is an active process. SPMs are biosynthesized from either omega-3 or omega-6 polyunsaturated fatty acids [2]. These endogenous mediators are produced by transcellular communication in a multistep process regulated by the enzymatic actions of lipoxygenases (LOX) and the acetylated form of cyclooxygenase-2 (Cox-2) [2]. Omega-3 derived SPMs include those of the resolvin, protectin and maresin families [3]. Bioactive products derived from omega-6 include the well-described prostaglandins (PGs), leukotrienes (LTs) as well as the SPMs lipoxins $[4,5]$.

PGs and LTs are derived from arachidonic acid and are the enzymatic products of Cox-1, Cox-2 and 5-LOX mediated pathways [4]. PGs and LTs are considered pro-inflammatory mediators important during the initial stages of inflammation [4]. On the other hand, lipoxins are alternative enzymatic products of arachidonic acid, that have proresolving properties during inflammation [6, 7]. Lipoxins are produced via transcellullar biosynthesis, examples being leukocyte-epithelial cell [8] or leukocyte-platelet interaction [9]. The lipid mediator profile produced by leukocytes can be altered through the lipid mediator class switch, a mechanism by which leukocytes stop production of proinflammatory mediators (i.e. PGs) and switch to the production of proresolution molecules (i.e. lipoxins) [6]. SPMs of the lipoxin family include $\mathrm{LXA}_{4}, \mathrm{LXB}_{4}$, as well as their isomeric isoforms aspirintriggered lipoxin (ATL) [6]. SPMs signal through specialized G-protein coupled receptors (GPCR) [10]. The once orphan ALX/FPR2, is now know to bind $\mathrm{LXA}_{4}$ with high affinity $[11,12]$.

The SPM family is diverse, and although all SPMs have proven or potential proresolving properties, their individual effects may be cell- and context-dependent. Little is known about the role of SPMs and their actions on B cells. However, we recently discovered that SPMs of the resolvin family are present in the spleen [13]. Furthermore, the SPM 17-

hydroxydosahexaenoic acid (17-HDHA) promoted B cell differentiation and increased antibody production [13]. In addition, other SPMs, including lipoxins, have been detected in blood, bone marrow and tonsil $[14,15]$. Lipoxins do have reported activity on some cells of the immune system. For example, $\mathrm{LXA}_{4}$ limits PMN chemotaxis and stimulates monocyte recruitment, it increases non-phlogistic macrophage uptake of apoptotic neutrophils and downregulates the release of pro-inflammatory mediators produced by dendritic cells and $\mathrm{T}$ cells [16-21]. In addition, lipoxins are proposed to have beneficial roles in inflammatory diseases, including periodontitis, colitis and asthma [22-25]. Severe asthmatic patients have decreased levels of $\mathrm{LXA}_{4}$ in their lungs [25]. Despite the known localization of lipoxins within $B$ cell-rich tissue, little is known about their potential impact on adaptive immunity, i.e. $\mathrm{B}$ cells and the humoral immune response. Here, we investigate $\mathrm{LXA}_{4}$ regulation of key human B cell functions.

\section{Results}

\section{Human peripheral blood B cells express and upregulate ALX/FPR2 upon activation}

$\mathrm{LXA}_{4}$ signals through its specific receptor ALX/FPR2 [10]. This GPCR is a member of the formyl peptide receptor (FPR) family [26], which has been identified in cells of the immune system including macrophages, T cells and also the promyelocytic leukemic cell line 60 (HL-60) [16, 27-30]. We first investigated whether human B cells contain ALX/FPR2 mRNA and protein. To test this, B cells were rigorously isolated from peripheral blood by positive selection and mRNA was collected. Members of the FPR family share a high degree of sequence homology [31]. Therefore, nested PCR was used to minimize non-specific amplification of other FPRs [32]. Semi-quantitative PCR results showed that human B cells, express ALX/FPR2 mRNA (Figure 1A-B). Next, ALX/FPR2 protein expression was 
measured on both B cells. Flow cytometry results showed that B cells express ALX/FPR2 on their surface at levels comparable to those of monocytes, a cell type which highly expresses ALX/FPR2 (Figure 1C-D) [27, 29]. In addition, the human B cell line JeKo-1, was found to express ALX/FPR2 mRNA (Figure 1E). Using shRNA, ALX/FPR 2 expression was knocked down (Figure $1 \mathrm{E}-\mathrm{G}$ ). These results show that both, primary human $B$ cells as well as human B cell lines, express ALX/FPR2 on their surface.

ALX/FPR2 expression can be upregulated on airway epithelial cells and infiltrating leukocytes after mitogen activation [24]. Therefore, to further confirm ALX/FPR2 protein expression, purified CD19+ $\mathrm{B}$ cells were cultured and activated with CpG ODN 2395 plus anti-IgM. ALX/FPR2 expression was measured using cell surface staining 24 hours and 48 hours after activation (Figure 1D-E). B cells stimulated strongly increased ALX/FPR2 expression over time compared to non-stimulated B cells.

\section{$\mathrm{LXA}_{4}$ decreased IgM and IgG production via ALX/FPR2-mediated signaling}

Lipoxins affect leukocyte functions such as neutrophil chemotaxis and dendritic cell cytokine production [33-35]. During the adaptive immune response, B cells are the effector cell that produces antibodies. Consequently, the effects of $\mathrm{LXA}_{4}$ on $\mathrm{B}$ cell antibody production were measured. Purified human $B$ cells from eight different individuals were pretreated with vehicle control or $\mathrm{LXA}_{4}$, followed by stimulation with CpG ODN 2395 plus anti-IgM. Supernatants were collected after 6 days of culture and IgM and IgG antibody levels were analyzed (Figure 2). Results showed that $\mathrm{LXA}_{4}$-treated $\mathrm{B}$ cells produced significantly lower IgM and IgG levels in all subjects (Figure 2A-B). In some cases, IgM was decreased as much as $88 \%$ and IgG by as much as $78 \%$

Other SPMs are known to signal through multiple SPM receptors. RvD1 for example, signals via both human GRP32 and ALX/FPR2 in mice and isolated cells [36]. Even though B cells express ALX/FPR2 on their surface, it is possible that $\mathrm{LXA}_{4}$ binds to other SPM receptors. The N-t-Butoxycarbonyl-phenylalanine-leucyl-phenylalanine-leucylphenylalanine (Boc-2) peptide is a commonly used ALX/FPR2 antagonist, which blocks $\mathrm{LXA}_{4}$ binding due to its tert-butyloxylcarbonyl group at the $\mathrm{N}$-terminus $[31,37]$. Therefore, Boc-2 was used to test whether $\mathrm{LXA}_{4}$ was signaling through ALX/FPR2 on B cells [38]. Purified $\mathrm{B}$ cells were pretreated with Boc-2, followed by $\mathrm{LXA}_{4}$ treatment and mitogen stimulation. IgM and IgG levels were measured after 6 days of culture (Figure 2C-D). Boc-2 effectively blocked the $\mathrm{LXA}_{4}$-mediated antibody decrease. These results show that $\mathrm{LXA}_{4}$ decreases $\mathrm{B}$ cell antibody production by interacting with ALX/FPR2.

ALX/FPR2 signaling in PMN inhibits LPS-induced nuclear translocation of nuclear factor$\mathrm{kB}$ (NF-kB) [39]. SPMs, such as RvD1 and $\mathrm{LxA}_{4}$ analogues have been shown to decrease NF-kB activation in human PMNs, leukocytes as well as in mouse models [39, 40]. Furthermore, NF- $\kappa \mathrm{B}$ is upregulated upon $\mathrm{B}$ cell activation and regulates $\mathrm{B}$ cell proliferation and differentiation [41]. Therefore NF- $\kappa \mathrm{B}$, specifically p65, nuclear translocation was measured after $\mathrm{LXA}_{4}$ treatment. Human B cells were pretreated with $\mathrm{LXA}_{4}$ followed by mitogen activation. Cells were harvested for either protein analysis or intracellular staining (Figure 3). Nuclear protein extract showed $\mathrm{LXA}_{4}$ decreased NF- $\mathrm{kB}(\mathrm{p} 65)$ translocation to the nucleus (Figure $3 \mathrm{~A}$ ). In addition, NF- $\kappa \mathrm{B}$ nuclear colocalization, as analyzed by ImageStream, confirmed a decreased in the percentage of cells translocating NF- $\kappa \mathrm{B}$ in the $\mathrm{LXA}_{4}$ treated group (Figure 3B-D).

\section{ALX/FPR2 is differentially express in naïve and memory $B$ cells}

The predominant $\mathrm{B}$ cell populations present in circulating blood are naïve and memory B cells. The ratio of naïve to memory B cells is variable among donors and is influenced by 
age and antigen exposure throughout life [42, 43]. In our initial experiments, we observed that ALX/FPR2 expression and antibody response to $\mathrm{LXA}_{4}$ was variable among different donors. As different donors have differences in $\mathrm{B}$ cell population distribution, we asked if $\mathrm{LXA}_{4}$ was affecting a specific $\mathrm{B}$ cell population. Peripheral B cells were stained for characteristic naïve and memory $\mathrm{B}$ cell surface markers and analyzed by flow cytometry. Results showed that naïve B cells $\left(\mathrm{CD} 19^{+} \mathrm{CD} 27^{-} \mathrm{IgD}^{+}\right)$and memory B cells $\left(\mathrm{CD} 19^{+}\right.$ $\mathrm{CD} 27^{+} \mathrm{IgD}^{-}$) express different levels of ALX/FPR2 (Figure 4A). Interestingly, memory B cells consistently expressed higher levels of ALX/FPR2 compared to naïve B cells.

Because ALX/FPR2 expression is upregulated upon B cell activation (Figure 1), ALX/FPR2 expression was measured on sorted naïve and memory B cells following mitogen stimulation. Purified B cells were stained and FACS sorted into naïve $\left(\mathrm{CD} 19^{+} \mathrm{CD} 27^{-}\right)$and memory $\left(\mathrm{CD} 19^{+} \mathrm{CD} 27^{+}\right) \mathrm{B}$ cell populations. Both naïve and memory B cells were treated with polyclonal activators or left untreated. B cells were collected 24, 48 and 72 hours after activation and ALX/FPR2 surface expression was measured in both naïve and memory $B$ cell populations (Figure 4B). At 24, 48 and 72 hours, non-treated naïve B cells expressed lower levels of ALX/FPR2 compared to memory cells. However, ALX/FPR2 expression on activated naïve B cells increased over time and reached levels similar to those on activated memory cells. On the other hand, non-stimulated memory B cells expressed a higher basal level of ALX/FPR2 on their surface, which was maintained over time.

\section{$\mathrm{LXA}_{4}$ decreases memory but not naïve $B$ cell antibody production}

Based on the differential expression of ALX/FPR2 on human B cell subsets, we asked if $\mathrm{LXA}_{4}$ preferentially influenced either memory or naïve B cell functions. Peripheral B cells were sorted into naïve $\left(\mathrm{CD} 19^{+} \mathrm{CD} 27^{-}\right)$and memory $\left(\mathrm{CD} 19^{+} \mathrm{CD} 27^{+}\right) \mathrm{B}$ cell fractions. Both cell populations were treated with $\mathrm{LXA}_{4}$ or vehicle control, followed by mitogen activation (Figure 5). After 6 days of culture, both cells and supernatants were collected and IgM and $\mathrm{IgG}$ production was measured (Figure $5 \mathrm{~A}-\mathrm{D}$ ). Interestingly, $\mathrm{LXA}_{4}$ treatment did not affect antibody production on naïve B cells (Figure 5A-B). In contrast, memory B cells, which constitutively express high levels of ALX/FPR2, had a 2-fold decrease in IgM and IgG production when treated with $\mathrm{LXA}_{4}$ (Figure 5C-D).

$\mathrm{LXA}_{4}$ did not affect the amount of antibodies produced per cell in neither naïve nor memory cells as analyzed by ELISpot (data not shown). In addition, the number of antibodysecreting cells present in the naïve $\mathrm{B}$ cell cultures treated with $\mathrm{LXA}_{4}$ did not change (Figure $5 \mathrm{~F}-\mathrm{G})$. However, $\mathrm{LXA}_{4}$ significantly decreased the number of antibody-secreting cells in the memory B cell cultures (Figure $5 \mathrm{H}-\mathrm{I}$ ). These results show that $\mathrm{LXA}_{4}$ selectively affects memory B cell antibody production, but not that of naïve B cells.

\section{$\mathrm{LXA}_{4}$ decreases memory but not naïve $B$ cell proliferation}

Upon mitogen encounter, B cells, particularly memory B cells, undergo rapid expansion and produce large amounts of antibody [44, 45]. Decreased proliferation could be at least partially responsible for the decreased antibody production and decreased number of antibody-secreting cells. Therefore, proliferation was measured on vehicle-and $\mathrm{LXA}_{4}$ treated B cells (Figure 6). Again, $\mathrm{LXA}_{4}$ did not affect naïve B cell proliferation (Figure 6A). Nonetheless, $\mathrm{LXA}_{4}$ significantly decreased memory B cell proliferation (Figure 6B). Following antigen recognition, both naïve and memory $\mathrm{B}$ cells can further differentiate. Naïve B cells can become memory or plasma cells, while antigen-cognate memory B cells can quickly differentiate into plasma cells capable of producing high-affinity antibodies [45]. Decreased differentiation could also be responsible for the $\mathrm{LXA}_{4}$-mediated antibody production decrease. In order to test these possibilities, $\mathrm{LXA}_{4}$-treated naïve and memory $\mathrm{B}$ cells populations were stained for $\mathrm{B}$ cell differentiation surface markers and naïve, memory, 
and antibody-secreting B cell populations were analyzed by flow cytometry (Supplemental figure 1). Results showed that $\mathrm{LXA}_{4}$ does not affect cell differentiation of naïve nor memory $\mathrm{B}$ cell populations. Lastly, $\mathrm{LXA}_{4}$ was not cytotoxic to $\mathrm{B}$ cells as it did not affect naïve nor memory B cell viability (Figure 6C-D).

\section{$\mathrm{LXA}_{4}$ decreases antigen-specific antibody production in vitro and in vivo}

Next, we tested the effects of $\mathrm{LXA}_{4}$ on mouse cells. Under in vitro conditions, $\mathrm{LXA}_{4}$ decreased mouse $\mathrm{B}$ cell antibody production (Figure 7C-D), as well as splenocyte proliferation (Figure 7E). $\mathrm{LXA}_{4}$ did not decrease cell viability (Figure 7F). Knowing that mouse $\mathrm{B}$ cells respond to $\mathrm{LXA}_{4}$, the effects of $\mathrm{LXA}_{4}$ on the memory $\mathrm{B}$ cell antibody response were measure in an in vivo immunization model. Using OVA as a model antigen, mice were immunized and treated with either $\mathrm{LXA}_{4}$ or vehicle control and the primary antibody response was measured after 2 weeks (Figure 8A-B). Interestingly, mice treated with $\mathrm{LXA}_{4}$ had a 4-fold decrease in OVA-specific IgM and a 2-fold decrease in OVAspecific IgG titers. Subsequently, a secondary challenge was performed and the antibodymediated response was analyzed (Figure 8C-D). Mice initially treated with $\mathrm{LXA}_{4}$ had a 6fold decrease in OVA-specific IgM titers and a non-significant decrease in OVA-specific IgG levels.

\section{Discussion}

To our knowledge, this is the first evidence describing the expression and function of ALX/ FPR2 on human B cells. The current study provides new important findings that demonstrate that primary B cells and the B cell line JeKo-1, express ALX/FPR2 on their surface. Furthermore, primary B cells upregulate ALX/FPR2 expression upon mitogen activation. Surprisingly, ALX/FPR2 is differentially expressed among naïve and memory B cell populations. Naïve B cells have lower basal expression of ALX/FPR2 which is upregulated following mitogen stimulation. On the other hand, memory B cells have higher expression levels of ALX/FPR2, which remain unchanged even after B cell activation.

$\mathrm{LXA}_{4}$ was found to potently decrease IgM and IgG antibody production in a dose-dependent manner. This effect is ALX/FPR2 dependent. Further analysis revealed that $\mathrm{LXA}_{4}$ specifically decreases antibody production and proliferation on memory B cells, but not on naïve $\mathrm{B}$ cells. Although $\mathrm{LXA}_{4}$ did not significantly decrease antibody production on naïve $\mathrm{B}$ cells, there was a decreasing trend in both, antibody production, as well as the number of antibody-secreting cells among all donors. This decrease in antibody production and antibody-secreting cells could be due to the increased expression of ALX/FPR2 following naïve B cells activation and differentiation into new memory B cells. The difference in ALX/FPR2 expression between naïve and memory B cells explains the specific effects of $\mathrm{LXA}_{4}$ on either B cell population. The complete signaling mechanism of ALX/FPR2 remains to be further studied and understood. However, it is possible that high ALX/FPR2 expression is needed for $\mathrm{LXA}_{4}$ to trigger a decrease in antibody production and proliferation, thus suggesting a signaling threshold as a control mechanism.

$\mathrm{NF}-\kappa \mathrm{B}$ activation is necessary for the initiation of a signaling cascade regulating $\mathrm{B}$ cell activation, proliferation and differentiation. Interestingly, $\mathrm{LXA}_{4}$ decreased NF- $\kappa \mathrm{B}$ translocation to the nucleus during $\mathrm{B}$ cell activation. In addition, $\mathrm{LXA}_{4}$ decreased memory $\mathrm{B}$ cell proliferation. It is possible that $\mathrm{LXA}_{4}$ decreases $\mathrm{B}$ cell proliferation by inhibiting NF- $\kappa \mathrm{B}$ signaling. Further study of the downstream signaling mechanism of ALX/FPR2 on human $B$ cells is necessary to better understand the effects of $\mathrm{LXA}_{4}$. Interestingly, $\mathrm{LXA}_{4}$ did not affect naïve nor memory B cell differentiation, nor was it cytotoxic to cells. Therefore, decreased $\mathrm{B}$ cell proliferation is at least partly responsible for the observed decreased antibody production by $\mathrm{LXA}_{4}$-treated memory B cells. $\mathrm{LXA}_{4}$-mediated decreased IgM and 
IgG antibody production has important implications in the development of antiinflammatory therapies.

Previous studies have shown using a collagen-induced arthritis mouse model, that the ALX/ FPR2 agonist, BML-111, decreased collagen-specific IgG2a titers [46]. In our study, $\mathrm{LXA}_{4}$ strongly decreased OVA-specific IgM and IgG production during the primary antibody response in vivo. Decreased antibody production further hindered the antibody memory response upon rechallenge particularly OVA-specific IgM production. Our findings provide proof-of-principle as to the role of $\mathrm{LXA}_{4}$ during the humoral immune response in vivo. There are many questions that have not been addressed and are the subject of future investigations. For example, whether the decreased antibody production in vivo is i) directly a result of $\mathrm{LXA}_{4}$ signaling on $\mathrm{B}$ cells, or ii) whether other important immunological processes, such as antigen presentation, are also affected. Our in vitro results showed that mouse $\mathrm{B}$ cells express the $\mathrm{LXA}_{4}$ receptor, and that treatment with $\mathrm{LXA}_{4}$ downregulates antibody production and proliferation. Therefore, it is possible that under physiological conditions, $\mathrm{LXA}_{4}$ directly affects $\mathrm{B}$ cells functions. On the other hand, $\mathrm{LXA}_{4}$ can decrease dendritic cell IL-12 production and migration to the splenic $\mathrm{T}$ cell zone following mitogen challenge in vivo, a process that can directly decrease antigen presentation [34]. Overall, it is important to further explore the effects of $\mathrm{LXA}_{4}$ on $\mathrm{B}$ cells and other cells of the adaptive immune system.

Although grouped as a family, individual SPMs can have different effects. We recently found that the SPM 17-HDHA increases antibody production while promoting B cell differentiation towards an antibody-secreting cell [13]. In addition, 17-HDHA increased expression of the transcription factor AID, which is involved in class switch recombination and somatic hypermutation, both important processes during antibody affinity maturation [13]. In the context of resolution, the effects of 17-HDHA on B cells are different, but not opposing to those of $\mathrm{LXA}_{4}$. While $\mathrm{LXA}_{4}$ decreased memory $\mathrm{B}$ cell proliferation and antibody production, 17-HDHA promoted B cell differentiation. Although $\mathrm{LXA}_{4}$ and 17HDHA are members of the SPM family, the effects of each SPM on the immune system may be context-dependent and cell-specific. Therefore, it is important to consider the nature of the inflammatory signal (i.e. trauma, pathogen, injury) and the balance of SPMs produced, would orchestrate the proper resolution program, thus assuring efficient immune protection.

SPMs are present in many tissues including tonsils, bone marrow and spleen [13-15, 4749]. Nevertheless, very little is known about SPM production during the adaptive immune response. In particular the microenvironment under which $\mathrm{B}$ cells are exposed to $\mathrm{LXA}_{4}$ and other SPMs. LOXs, which regulate the enzymatic production of SPMs, are found in multiple cells of the immune system including neutrophils, monocytes, macrophages, mast cells and B cells [50]. It is possible that B cells and other immune cells produce SPMs such as $\mathrm{LXA}_{4}$. Importantly, not all SPMs are produced simultaneously. For example, RvD3 is produced during the late stages of resolution, unlike RvD1 and RvD2, which are present in the early resolution phase [51]. The implications for the temporal regulation of SPMs are not fully understood. Therefore, it is important to better understand the microenvironment and kinetics under which B cells are exposed to different SPMs, such as $\mathrm{LXA}_{4}$.

Memory B cells are responsible for the antibody-mediated adaptive immune response which confers long-term protection against infiltrating pathogens. The effects of $\mathrm{LXA}_{4}$ on human memory B cells provide a link between resolution signals and adaptive immunity. Decreased antibody production following antigen clearance is beneficial in returning to a homeostatic state and preventing unwanted inflammation. However, a reduced antibody-mediated response can have detrimental consequences with respect to fighting infiltrating pathogens. 
In fact, microorganisms such as Toxoplasma gondii and Mycobacterium tuberculosis already take advantage of $\mathrm{LXA}_{4}$-proresolving properties in order to avoid immune-surveillance recognition [35, 48, 52]. It is critical to further study the role of lipoxins and other SPMs during the adaptive immune response. This is particularly important in the field of vaccinology and autoimmune disorders. For example, it is possible that a diet rich in omega-6, which favors $\mathrm{LXA}_{4}$ production, could decrease vaccination efficiency. On the other hand, decreasing antibody production against self-antigens can be beneficial for the development of new therapies against autoimmune disorders.

\section{Materials and Methods}

\section{Human B lymphocyte isolation}

Peripheral blood B cells were purified from healthy human donors under the ethical permission provided by the Research Subjects Review Board at the University of Rochester. Buffy coat was extracted from whole blood and suspended in 1 x PBS. Ficoll-Paque (Amersham Biosciences, Piscataway, NJ) gradient centrifugation was then performed to isolate PBMCs [53, 54]. B cell purification was done using CD19 Dynabeads and CD19 Detachabead (Invitrogen, Carlsbad, CA), cell purity was $>98 \% \mathrm{CD}^{+} 9^{+}[43,53,54]$. In addition, purified human B cells were stained and sorted using CD19 (clone SJ25C1 or HIB19, BD bioscience, San Jose, CA), CD27 (clone M-T271, BD bioscience, San Jose, CA) and sorted using a FACSAria cell sorter (BD bioscience, San Jose, CA), purity > $>8 \%$ [43].

\section{Reagents and culture conditions}

Purified human B cells or mouse splenocytes were cultured in RPMI 1640 (GIBCO/ Invitrogen, Carlsbad, CA) and supplemented with $5 \%$ fetal bovine serum, $2 \mathrm{mM} \mathrm{L-}$ glutamine, $5 \times 10-5 \mathrm{M}$ 2-ME, $10 \mathrm{mM}$ HEPES and $50 \mu \mathrm{g} / \mathrm{mL}$ gentamicin. Human B cells were cultured $1 \times 10^{6}$ cells $/ \mathrm{ml}$ and stimulated with the indicated mixtures of CpG ODN 2395 sequence 5'-TCGTCGTTTTCGGCGCGCGCCG-3' ( $1 \mu \mathrm{g} / \mathrm{mL}$ ) (Coley Pharmaceutical Group, Wellesley, MA), rabbit anti-human IgM antibody fragment $(2 \mu \mathrm{g} / \mathrm{mL})$ (Jackson ImmunoResearch Laboratories, West Grove, PA), F(ab') 2 goat anti-human IgG (anti-Ig) (2 $\mu \mathrm{g} / \mathrm{mL}$ ), (Jackson ImmunoResearch Laboratories, West Grove, PA), or pansorbin (1:1000) (Staphylococcus aureus Cowen I strain; Sigma-Aldrich). Mouse splenocytes were cultured at $1 \times 10^{6}$ cells $/ \mathrm{ml}$ for up to 6 days and stimulated with LPS (E. coli 055:B5, Sigma) (1 $\mu \mathrm{g} /$ $\mathrm{ml}$ ). Lipoxin $\mathrm{A}_{4}$ (Calbiochem, Merk KGaA, Darmstadt, Germany) was suspended in ethanol, vehicle controls were defined as $1 \mathrm{x}$ PBS with $0.03 \%$ ethanol by volume, equivalent to $100 \mathrm{nM} \mathrm{LXA}_{4}$. $\mathrm{LXA}_{4}$ or vehicle control were added to cell culture 30 minutes before stimulating $\mathrm{B}$ cells or splenocytes with corresponding mitogens. $\mathrm{LXA}_{4}$ or vehicle treatments were continued for the duration of the culture. In experiments using the ALX/FPR2 antagonist N-Boc-Phe-Leu-Phe-Leu-Phe (Boc-2) (GeneScript, Piscataway, NJ), Boc-2 was added at the 30 min prior $\mathrm{LXA}_{4}$ treatment. The human embryonic kidney 293 (HEK293) and promyelocytic HL-60 cell lines were purchased from the American Type Culture Collection (Manassas, VA). HL-60 differentiation was induced using $1 \mu \mathrm{M}$ retinoic acid (Sigma, Saint Louis, MO) [55]. The human mantle cell lymphoma cell line, JeKo-1, was purchased from American Type Culture Collection (Manassas, VA).

\section{Polymerase chain reaction}

Primary B cells were cultured for 48 hours $\left(6 \times 10^{6}\right.$ cells $/ \mathrm{ml}, 500 \mu \mathrm{l} /$ well $)$ and harvested for RNA collection using the Qiagen RNAeasy mini kit (Valencia, CA). RNA was reversed transcribed using Superscript III and random primers (Invitrogen, Carlsbad, CA). ALX/ FPR2 message expression was amplified by nested PCR [32]. Outer primers forward 5'CTGCTGGTGCTGCTGGCAAG-3' and reverse 5'-AATATCCCTGACCCCATCCTC-3' $\left(1.1 \mathrm{~Kb}\right.$ fragment), were used in a 40 cycle PCR reaction (annealing temperature, $61^{\circ} \mathrm{C}$ ), 
followed by inner primers forward 5'-TGCTTGGGGTCACCTTTGTC-3' and reverse 5'TGAAGCAGAATTGGCAGCCG-3' (950 bp fragment) (annealing temperature, $59^{\circ} \mathrm{C}$ ). $7 \mathrm{~S}$ message expression was amplified using the forward primer 5'ACCACCAGGTTGCCTAAGGA-3' and the reverse primer 5'CACGGGAGTTTTGACCTGCT-3' in a 30 cycle PCR reaction (annealing temperature, $60^{\circ} \mathrm{C}$ ). PrimePCR SYBR Green Assays were used to amplify human CD14, CD3 and CD11b expression as suggested by the manufacturer (Bio-Rad, Hercules, CA). Results were analyzed using Bio-Rad iCycler software (Bio-Rad, Hercules, CA).

\section{shRNA transfection}

ALX/FPR2 expression was knocked down in human JeKo-1 B cells using SureSilencing shRNA plasmid as suggested by manufacturer (Qiagen, Valencia, CA). In brief, JeKo-1 cells were cultured in RPMI 1640 (GIBCO/Invitrogen, Carlsbad, CA) and supplemented with $10 \%$ fetal bovine serum, $2 \mathrm{mM}$ L-glutamine, $5 \times 10-5 \mathrm{M}$ 2-ME, $10 \mathrm{mM}$ HEPES and 50 $\mu \mathrm{g} / \mathrm{mL}$ gentamicin. Plasmids containing either ALX/FPR2 shRNA or control shRNA were introduced into cells by electroporation. Stably transfected cells were selected using Puromycin. Cells were then harvested for mRNA and protein analysis.

\section{Cell staining}

B cells were stained for surface markers with a mixture of fluorochrome-conjugated antibodies which include: CD19 (clone SJ25C1 or HIB19, BD bioscience, San Jose, CA), CD27 (clone M-T271, BD bioscience, San Jose, CA), CD38 (clone HIT2, BD bioscience, San Jose, CA), IgD (clone IA6-2, BD bioscience, San Jose, CA), IgM (clone G20-127, BD bioscience, San Jose, CA), IgG (clone G18-145, BD bioscience, San Jose, CA), FPRL-1 (clone 304405, R\&D systems, Minneapolis, MN), CD14 ( M5E2, BD bioscience, San Jose, CA), fluorochrome-conjugated anti-mouse (Jackson ImmunoResearch, West Grove, PA) if non-conjugated antibody was included in the staining panel. Mouse splenocytes were stained with CD19 (clone 1D3, BD bioscience, San Jose, CA), B220 (clone RA3-6B2, eBioscience, San Diego, CA), CD3 (clone 145-2C11, Biolegend, San Diego, CA). All samples were stained for viability using 7AAD Cell Viability Solution (BD bioscience, San Jose, CA). Fluorescence minus one (FMO) controls were included in each staining protocol. Samples were run on a 12-color LSRII flow cytometer (BD bioscience, San Jose, CA) and analyzed by FlowJo software (Tree Star Inc., Ashland, OR).

\section{ELISA and ELISpot assays}

$\mathrm{CD} 19^{+}$human B cells or mouse splenocytes were cultured in 96-well plates and treated for 6 days as described above. Supernatants from cultured cells were collected and IgM and IgG levels were measured by ELISA quantification kit as specified by the manufacturer (Bethyl Laboratories, Montgomery, TX). Ovalbumin (OVA)-specific antibodies were measured using pre-coated OVA $(10 \mu \mathrm{g} / \mathrm{ml})$ plates and mouse-specific IgM and IgG ELISA kits (Bethyl Laboratories, Montgomery, TX). For ELISpot analysis, cells were cultured for 5 days and transferred to ELISpot plates (Millipore, Billerica, MA) coated with either goat anti-IgM or IgG antibodies (Biosource, Carlsbad, CA) as recommended by the manufacturer. Alkaline phosphatase-conjugated goat anti-human IgG (Jackson ImmunoResearch Laboratories) or anti-human IgM antibody (Biosource, Carlsbad, CA) was used to detect spots and developed using Vector AP substrate kit III (Vector Laboratories, Burlingame, CA). Spots were counted using a CTL plate reader and analyzed by ImmunoSpot software (Cellular Technologies, Shaker Heights, OH). 


\section{Western blot}

Purified B cells were cultured $\left(6 \times 10^{6}\right.$ cells $\left./ \mathrm{ml}, 500 \mu \mathrm{l} / \mathrm{well}\right)$ and treated as described in the Results section. Cells were harvested for protein extraction as specified by the manufacturer of the Nuclear Extraction Kit (Active Motif, Carlsbad, CA). Gradient SDS-PAGE gels (Pierce/Thermo Fisher Scientific, Rockford, IL) were loaded with $5 \mu \mathrm{g}$ of protein and transferred to PVDF membranes (Millipore, Billerica, MA). Membrane was probed with p65 (clone F-6, Santa Cruz Biotechnology, Santa Cruz, CA), beta-tubulin (Abcam, Cambridge, MA), actin (Calbiochem/EMD Chemicals, Gibbstown, NJ) and HRP conjugated goat anti-mouse or goat anti-rabbit antibodies (Jackson ImmunoResearch Laboratories, West Grove, PA). ECL reagent (Perkin Elmer Life Sciences Inc., Boston, MA) was use to visualize Western blots.

\section{ImageStream}

B cells were fixed using 4\% paraformaldehyde EM grade (Electron Microscopy Sciences, Hatfield, PA) and permeabilized with BD phosflow PermBuffer III (BD bioscience, San Jose, CA). Cells were stained with anti-CD19 (clone HIB19, BD bioscience, San Jose, CA), anti-p65 (clone C-20, Santa Cruz Biotechnology, Santa Cruz, CA), DRAQ5 (Cell Signaling Technology, Danvers, MA) and a fluorochrome-conjugate anti-rabbit IgG if a nonconjugated antibody was used (Invitrogen, Grand Island, NY). Samples were run on an ImageStream X (Amnis Corporation, Seattle, WA), and analyzed using IDEAS software (Amnis Corporation, Seattle, WA).

\section{Proliferation assay}

Purified B cells or mouse splenocytes were cultured for 6 days in 96 -well plates $\left(1 \times 10^{5}\right.$ cells $/ \mathrm{ml}, 200 \mu \mathrm{l} /$ well). $\left[{ }^{3} \mathrm{H}\right]$ Thymidine $(1 \mu \mathrm{Ci} /$ well) was added 12 hours before sample collection, as previously described $[56,57]$. $\left[{ }^{3} \mathrm{H}\right]$ Thymidine incorporation was then measured by scintillation spectroscopy using a Topcount Luminometer (PerkinElmer, Boston, MA).

\section{In vivo immunization}

C57BL/6J mice, 8-10 weeks old were (The Jackson Laboratory, Bar Harbor, ME) immunized with $10 \mu \mathrm{g}$ OVA adsorbed onto complete Freund's adjuvant (CFA) (SigmaAldrich, St. Louis, MO) (1:1 ratio) delivered by intraperitoneal (i.p.) injection. Mice were then given $1 \mu \mathrm{g}$ lipoxin $\mathrm{A}_{4}$ (Calbiochem, Merk KGaA, Darmstadt, Germany) (suspended in $1 \times$ PBS) or vehicle control (defined as $1 \times$ PBS with $0.04 \%$ ethanol by volume) by i.p. injection. Serum was collected 2 weeks after primary immunization and antibody levels were measured by ELISA as described above. Ten weeks after primary immunization, mice were given a second challenge using $10 \mu \mathrm{g}$ OVA (suspended in PBS) delivered i.p. Sera were collected 2 weeks after secondary immunization and use for antibody ELISA.

\section{Statistical analysis}

Results are expressed as mean \pm SEM. Significance was determined by statistical analysis using a two-tailed paired Student t-test with a Wilcoxon matches-pairs signed rank test or a two-way ANOVA with a Bonferroni posttest where two or more variables were included. Unpaired t-test analysis was used when analyzing mouse groups. All tests were carried out using GraphPad Prism 5 (GraphPad Software, La Jolla, CA). Probability values of $p \leq 0.05$ were considered statistically significant

\section{Supplementary Material}

Refer to Web version on PubMed Central for supplementary material. 


\section{Acknowledgments}

This work was supported by NIH grants AI103690 (to RPP), GM038765 (to CNS) and T90 DE021985 (University of Rochester Medical Center).

\section{Abbreviation list}

$\begin{array}{ll}\text { SPMs } & \text { Specialized proresolving mediators } \\ \text { LXA4 } & \text { lipoxin } \mathrm{A}_{4} \\ \text { FPR } & \text { formyl peptide receptor } \\ \text { PGs } & \text { prostaglandins } \\ \text { LTs } & \text { leukotrienes } \\ \text { LOXs } & \text { lipoxygenases } \\ \text { Cox } & \text { cyclooxygenase }\end{array}$

\section{References}

1. Serhan CN, Clish CB, Brannon J, Colgan SP, Chiang N, Gronert K. Novel functional sets of lipidderived mediators with antiinflammatory actions generated from omega- 3 fatty acids via cyclooxygenase 2-nonsteroidal antiinflammatory drugs and transcellular processing. J Exp Med. 2000; 192:1197-1204. [PubMed: 11034610]

2. Serhan CN, Chiang N, Van Dyke TE. Resolving inflammation: dual anti-inflammatory and proresolution lipid mediators. Nat Rev Immunol. 2008; 8:349-361. [PubMed: 18437155]

3. Serhan CN, Petasis NA. Resolvins and protectins in inflammation resolution. Chem Rev. 2011; 111:5922-5943. [PubMed: 21766791]

4. Harris SG, Padilla J, Koumas L, Ray D, Phipps RP. Prostaglandins as modulators of immunity. Trends Immunol. 2002; 23:144-150. [PubMed: 11864843]

5. Haeggstrom JZ, Funk CD. Lipoxygenase and Leukotriene Pathways: Biochemistry, Biology, and Roles in Disease. Chemical Reviews. 2011; 111:5866-5898. [PubMed: 21936577]

6. Serhan CN. Lipoxins and aspirin-triggered 15-epi-lipoxins are the first lipid mediators of endogenous anti-inflammation and resolution. Prostaglandins Leukot Essent Fatty Acids. 2005; 73:141-162. [PubMed: 16005201]

7. Parkinson JF. Lipoxin and synthetic lipoxin analogs: an overview of anti-inflammatory functions and new concepts in immunomodulation. Inflamm Allergy Drug Targets. 2006; 5:91-106. [PubMed: 16613568]

8. Levy BD, Romano M, Chapman HA, Reilly JJ, Drazen J, Serhan CN. Human alveolar macrophages have 15-lipoxygenase and generate $15(\mathrm{~S})$-hydroxy-5,8,11-cis-13-trans-eicosatetraenoic acid and lipoxins. J Clin Invest. 1993; 92:1572-1579. [PubMed: 8376607]

9. Serhan CN, Sheppard KA. Lipoxin formation during human neutrophil-platelet interactions. Evidence for the transformation of leukotriene A4 by platelet 12-lipoxygenase in vitro. J Clin Invest. 1990; 85:772-780. [PubMed: 2155925]

10. Serhan CN, Krishnamoorthy S, Recchiuti A, Chiang N. Novel anti-inflammatory--pro-resolving mediators and their receptors. Curr Top Med Chem. 2011; 11:629-647. [PubMed: 21261595]

11. Fiore S, Maddox JF, Perez HD, Serhan CN. Identification of a human cDNA encoding a functional high affinity lipoxin A4 receptor. J Exp Med. 1994; 180:253-260. [PubMed: 8006586]

12. Dufton N, Hannon R, Brancaleone V, Dalli J, Patel HB, Gray M, D’Acquisto F, Buckingham JC, Perretti M, Flower RJ. Anti-inflammatory role of the murine formyl-peptide receptor 2: ligandspecific effects on leukocyte responses and experimental inflammation. J Immunol. 2010; 184:2611-2619. [PubMed: 20107188] 
13. Ramon S, Gao F, Serhan CN, Phipps RP. Specialized proresolving mediators enhance human B cell differentiation to antibody-secreting cells. J Immunol. 2012; 189:1036-1042. [PubMed: 22711890]

14. Poulsen RC, Gotlinger KH, Serhan CN, Kruger MC. Identification of inflammatory and proresolving lipid mediators in bone marrow and their lipidomic profiles with ovariectomy and omega-3 intake. Am J Hematol. 2008; 83:437-445. [PubMed: 18429055]

15. Schneider C, Keeney DS, Boeglin WE, Brash AR. Detection and cellular localization of 12Rlipoxygenase in human tonsils. Arch Biochem Biophys. 2001; 386:268-274. [PubMed: 11368351]

16. Ariel A, Chiang N, Arita M, Petasis NA, Serhan CN. Aspirin-triggered lipoxin A4 and B4 analogs block extracellular signal-regulated kinase-dependent TNF-alpha secretion from human T cells. J Immunol. 2003; 170:6266-6272. [PubMed: 12794159]

17. Godson C, Mitchell S, Harvey K, Petasis NA, Hogg N, Brady HR. Cutting edge: lipoxins rapidly stimulate nonphlogistic phagocytosis of apoptotic neutrophils by monocyte-derived macrophages. J Immunol. 2000; 164:1663-1667. [PubMed: 10657608]

18. Lee TH, Horton CE, Kyan-Aung U, Haskard D, Crea AE, Spur BW. Lipoxin A4 and lipoxin B4 inhibit chemotactic responses of human neutrophils stimulated by leukotriene B4 and N-formyl-Lmethionyl-L-leucyl-L-phenylalanine. Clinical Science. 1989; 77:195-203. [PubMed: 2548801]

19. Takano T, Clish CB, Gronert K, Petasis N, Serhan CN. Neutrophil-mediated changes in vascular permeability are inhibited by topical application of aspirin-triggered 15-epi-lipoxin A4 and novel lipoxin B4 stable analogues. J Clin Invest. 1998; 101:819-826. [PubMed: 9466977]

20. Colgan SP, Serhan CN, Parkos CA, Delp-Archer C, Madara JL. Lipoxin A4 modulates transmigration of human neutrophils across intestinal epithelial monolayers. J Clin Invest. 1993; 92:75-82. [PubMed: 8326019]

21. Devchand PR, Arita M, Hong S, Bannenberg G, Moussignac RL, Gronert K, Serhan CN. Human ALX receptor regulates neutrophil recruitment in transgenic mice: roles in inflammation and host defense. Faseb J. 2003; 17:652-659. [PubMed: 12665478]

22. Arita M, Yoshida M, Hong S, Tjonahen E, Glickman JN, Petasis NA, Blumberg RS, Serhan CN. Resolvin E1, an endogenous lipid mediator derived from omega-3 eicosapentaenoic acid, protects against 2,4,6-trinitrobenzene sulfonic acid-induced colitis. Proc Natl Acad Sci U S A. 2005; 102:7671-7676. [PubMed: 15890784]

23. Hasturk H, Kantarci A, Ohira T, Arita M, Ebrahimi N, Chiang N, Petasis NA, Levy BD, Serhan CN, Van Dyke TE. RvE1 protects from local inflammation and osteoclast- mediated bone destruction in periodontitis. Faseb J. 2006; 20:401-403. [PubMed: 16373400]

24. Levy BD, De Sanctis GT, Devchand PR, Kim E, Ackerman K, Schmidt BA, Szczeklik W, Drazen JM, Serhan CN. Multi-pronged inhibition of airway hyper-responsiveness and inflammation by lipoxin A(4). Nat Med. 2002; 8:1018-1023. [PubMed: 12172542]

25. Bonnans C, Chanez P, Chavis C. Lipoxins in asthma: potential therapeutic mediators on bronchial inflammation? Allergy. 2004; 59:1027-1041. [PubMed: 15355460]

26. Migeotte I, Communi D, Parmentier M. Formyl peptide receptors: a promiscuous subfamily of G protein-coupled receptors controlling immune responses. Cytokine Growth Factor Rev. 2006; 17:501-519. [PubMed: 17084101]

27. Maddox JF, Hachicha M, Takano T, Petasis NA, Fokin VV, Serhan CN. Lipoxin A4 stable analogs are potent mimetics that stimulate human monocytes and THP-1 cells via a G-protein-linked lipoxin A4 receptor. J Biol Chem. 1997; 272:6972-6978. [PubMed: 9054386]

28. Simiele F, Recchiuti A, Mattoscio D, De Luca A, Cianci E, Franchi S, Gatta V, Parolari A, Werba JP, Camera M, Favaloro B, Romano M. Transcriptional regulation of the human FPR2/ALX gene: evidence of a heritable genetic variant that impairs promoter activity. Faseb J. 2012; 26:13231333. [PubMed: 22131270]

29. Waechter V, Schmid M, Herova M, Weber A, Gunther V, Marti-Jaun J, Wust S, Rosinger M, Gemperle C, Hersberger M. Characterization of the promoter and the transcriptional regulation of the lipoxin A4 receptor (FPR2/ALX) gene in human monocytes and macrophages. J Immunol. 2012; 188:1856-1867. [PubMed: 22246625]

30. Fiore S, Romano M, Reardon EM, Serhan CN. Induction of functional lipoxin A4 receptors in HL-60 cells. Blood. 1993; 81:3395-3403. [PubMed: 8389617] 
31. Ye RD, Boulay F, Wang JM, Dahlgren C, Gerard C, Parmentier M, Serhan CN, Murphy PM. International Union of Basic and Clinical Pharmacology. LXXIII. Nomenclature for the formyl peptide receptor (FPR) family. Pharmacol Rev. 2009; 61:119-161. [PubMed: 19498085]

32. Sodin-Semrl S, Taddeo B, Tseng D, Varga J, Fiore S. Lipoxin A4 inhibits IL-1 beta-induced IL-6, IL-8, and matrix metalloproteinase-3 production in human synovial fibroblasts and enhances synthesis of tissue inhibitors of metalloproteinases. J Immunol. 2000; 164:2660-2666. [PubMed: 10679106]

33. Serhan CN, Maddox JF, Petasis NA, Akritopoulou-Zanze I, Papayianni A, Brady HR, Colgan SP, Madara JL. Design of lipoxin A4 stable analogs that block transmigration and adhesion of human neutrophils. Biochemistry. 1995; 34:14609-14615. [PubMed: 7578068]

34. Aliberti J, Hieny S, Reis e, Sousa C, Serhan CN, Sher A. Lipoxin-mediated inhibition of IL-12 production by DCs: a mechanism for regulation of microbial immunity. Nat Immunol. 2002; 3:7682. [PubMed: 11743584]

35. Aliberti J, Serhan C, Sher A. Parasite-induced lipoxin A4 is an endogenous regulator of IL-12 production and immunopathology in Toxoplasma gondii infection. J Exp Med. 2002; 196:12531262. [PubMed: 12417634]

36. Krishnamoorthy S, Recchiuti A, Chiang N, Yacoubian S, Lee CH, Yang R, Petasis NA, Serhan CN. Resolvin D1 binds human phagocytes with evidence for proresolving receptors. Proc Natl Acad Sci U S A. 2010; 107:1660-1665. [PubMed: 20080636]

37. Machado FS, Johndrow JE, Esper L, Dias A, Bafica A, Serhan CN, Aliberti J. Anti-inflammatory actions of lipoxin A4 and aspirin-triggered lipoxin are SOCS-2 dependent. Nat Med. 2006; 12:330-334. [PubMed: 16415877]

38. Stenfeldt AL, Karlsson J, Wenneras C, Bylund J, Fu H, Dahlgren C. Cyclosporin H, Boc-MLF and Boc-FLFLF are antagonists that preferentially inhibit activity triggered through the formyl peptide receptor. Inflammation. 2007; 30:224-229. [PubMed: 17687636]

39. Jozsef L, Zouki C, Petasis NA, Serhan CN, Filep JG. Lipoxin A4 and aspirin-triggered 15-epilipoxin A4 inhibit peroxynitrite formation, NF-kappa B and AP-1 activation, and IL-8 gene expression in human leukocytes. Proc Natl Acad Sci U S A. 2002; 99:13266-13271. [PubMed: 12235371]

40. Wang B, Gong X, Wan JY, Zhang L, Zhang Z, Li HZ, Min S. Resolvin D1 protects mice from LPS-induced acute lung injury. Pulm Pharmacol Ther. 2011; 24:434-441. [PubMed: 21501693]

41. Thomas MD, Srivastava B, Allman D. Regulation of peripheral B cell maturation. Cell Immunol. 2006; 239:92-102. [PubMed: 16797504]

42. Paganelli R, Quinti I, Fagiolo U, Cossarizza A, Ortolani C, Guerra E, Sansoni P, Pucillo LP, Scala E, Cozzi E, et al. Changes in circulating B cells and immunoglobulin classes and subclasses in a healthy aged population. Clin Exp Immunol. 1992; 90:351-354. [PubMed: 1424294]

43. Bancos S, Phipps RP. Memory B cells from older people express normal levels of cyclooxygenase-2 and produce higher levels of IL-6 and IL-10 upon in vitro activation. Cell Immunol. 2010; 266:90-97. [PubMed: 20889146]

44. Lanzavecchia A, Sallusto F. Human B cell memory. Curr Opin Immunol. 2009; 21:298-304. [PubMed: 19497721]

45. Schmidlin H, Diehl SA, Blom B. New insights into the regulation of human B-cell differentiation. Trends Immunol. 2009; 30:277-285. [PubMed: 19447676]

46. Zhang L, Zhang X, Wu P, Li H, Jin S, Zhou X, Li Y, Ye D, Chen B, Wan J. BML-111, a lipoxin receptor agonist, modulates the immune response and reduces the severity of collagen-induced arthritis. Inflamm Res. 2008; 57:157-162. [PubMed: 18648754]

47. Dona M, Fredman G, Schwab JM, Chiang N, Arita M, Goodarzi A, Cheng G, von Andrian UH, Serhan CN. Resolvin E1, an EPA-derived mediator in whole blood, selectively counterregulates leukocytes and platelets. Blood. 2008; 112:848-855. [PubMed: 18480426]

48. Bafica A, Scanga CA, Serhan C, Machado F, White S, Sher A, Aliberti J. Host control of Mycobacterium tuberculosis is regulated by 5-lipoxygenase-dependent lipoxin production. J Clin Invest. 2005; 115:1601-1606. [PubMed: 15931391] 
49. Hong S, Porter TF, Lu Y, Oh SF, Pillai PS, Serhan CN. Resolvin E1 metabolome in local inactivation during inflammation-resolution. J Immunol. 2008; 180:3512-3519. [PubMed: 18292578]

50. Steinhilber D, Radmark O, Samuelsson B. Transforming growth factor beta upregulates 5lipoxygenase activity during myeloid cell maturation. Proc Natl Acad Sci U S A. 1993; 90:59845988. [PubMed: 8327471]

51. Dalli J, Winkler JW, Colas RA, Arnardottir H, Cheng CY, Chiang N, Petasis NA, Serhan CN. Resolvin D3 and aspirin-triggered resolvin D3 are potent immunoresolvents. Chem Biol. 2013; 20:188-201. [PubMed: 23438748]

52. Chen M, Divangahi M, Gan H, Shin DS, Hong S, Lee DM, Serhan CN, Behar SM, Remold HG. Lipid mediators in innate immunity against tuberculosis: opposing roles of PGE2 and LXA4 in the induction of macrophage death. J Exp Med. 2008; 205:2791-2801. [PubMed: 18955568]

53. Bernard MP, Phipps RP. CpG oligodeoxynucleotides induce cyclooxygenase-2 in human B lymphocytes: implications for adjuvant activity and antibody production. Clin Immunol. 2007; 125:138-148. [PubMed: 17728187]

54. Ryan EP, Pollock SJ, Murant TI, Bernstein SH, Felgar RE, Phipps RP. Activated human B lymphocytes express cyclooxygenase- 2 and cyclooxygenase inhibitors attenuate antibody production. J Immunol. 2005; 174:2619-2626. [PubMed: 15728468]

55. Breitman TR, Selonick SE, Collins SJ. Induction of differentiation of the human promyelocytic leukemia cell line (HL-60) by retinoic acid. Proc Natl Acad Sci U S A. 1980; 77:2936-2940. [PubMed: 6930676]

56. Garcia-Bates TM, Bernstein SH, Phipps RP. Peroxisome proliferator-activated receptor gamma overexpression suppresses growth and induces apoptosis in human multiple myeloma cells. Clin Cancer Res. 2008; 14:6414-6425. [PubMed: 18927280]

57. Alisi A, Giannini C, Spaziani A, Caini P, Zignego AL, Balsano C. Involvement of PI3K in HCVrelated lymphoproliferative disorders. J Cell Physiol. 2008; 214:396-404. [PubMed: 17654494] 
A)

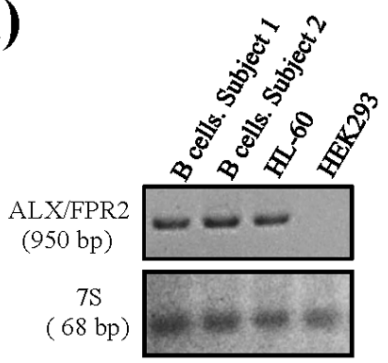

B)
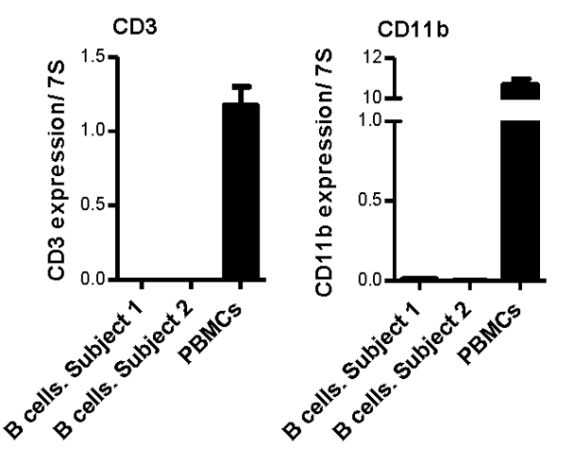

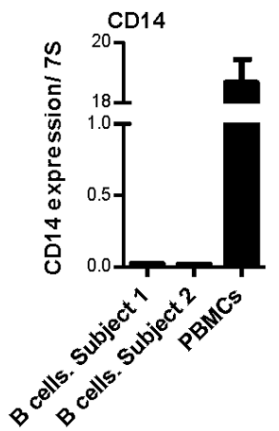

C)

D)
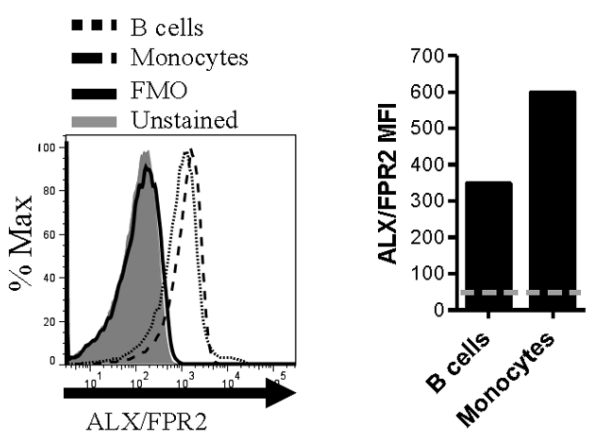

E)

F)
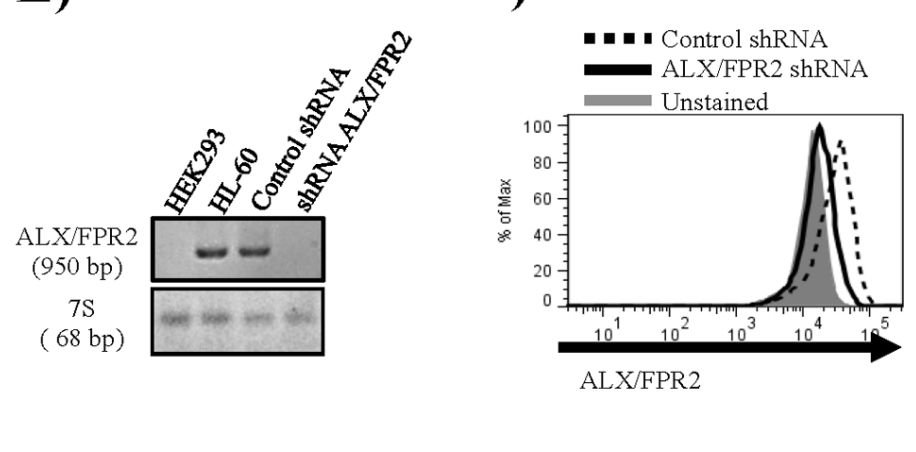

H)

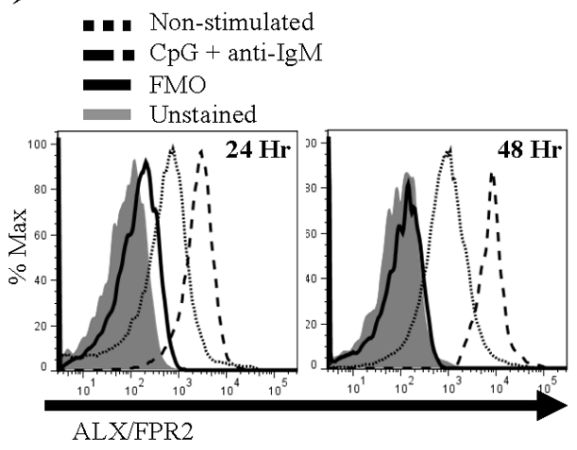

I)

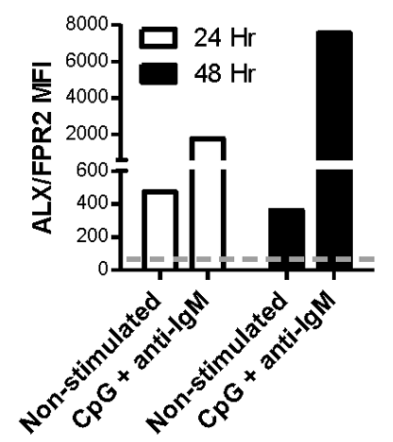

Figure 1. Human B cells express ALX/FPR2

A) Human $\mathrm{CD} 19^{+} \mathrm{B}$ cells were isolated by magnetic bead purification and sorted for CD19+ cells. B cell ALX/FPR2 mRNA expression was amplified by nested semi-quantitative PCR. Differentiated HL-60 and HEK293 cell lines were used as positive and negative controls, respectively. B) To exclude the presence of contaminating ALX/FPR2 mRNA derived from other peripheral blood mononuclear cells (PBMCs), expression levels of CD3, CD11b and CD14 was measured by real-time PCR. CD3, CD11b and CD14 expressions were normalized to 7S. C) PBMCs were isolated from healthy subjects and ALX/FPR expression was analyzed by flow cytometry. Cells were gated on the live lymphocyte gate and B cells $\left(\mathrm{CD} 19^{+}\right)$and monocytes $\left(\mathrm{CD} 14^{+}\right)$were analyzed. D) Quantification of ALX/FPR2 
expression on primary B cells and monocytes showed as mean fluorescence intensity (MFI) (gray dotted line represents background signal). E) JeKo-1 cells were transfected with ALX/ FPR2 shRNA and mRNA knockdown was confirmed by nested PCR analysis. F) ALX/ FPR2 protein knockdown was confirmed in JeKo-1 cells by flow cytometry analysis. G) Quantification of ALX/FPR2 expression on JeKo-1 cells. H) Primary B cells were either left non-stimulated or activated with CpG ODN 2395 plus anti-IgM. Here is shown a representative histogram of ALX/FPR2 expression analyzed by flow cytometry. Cells were gated on the live lymphocyte gate CD19+ population. I) Quantification of ALX/FPR2 expression. Gray dotted line represents background signal. 
A)

B)
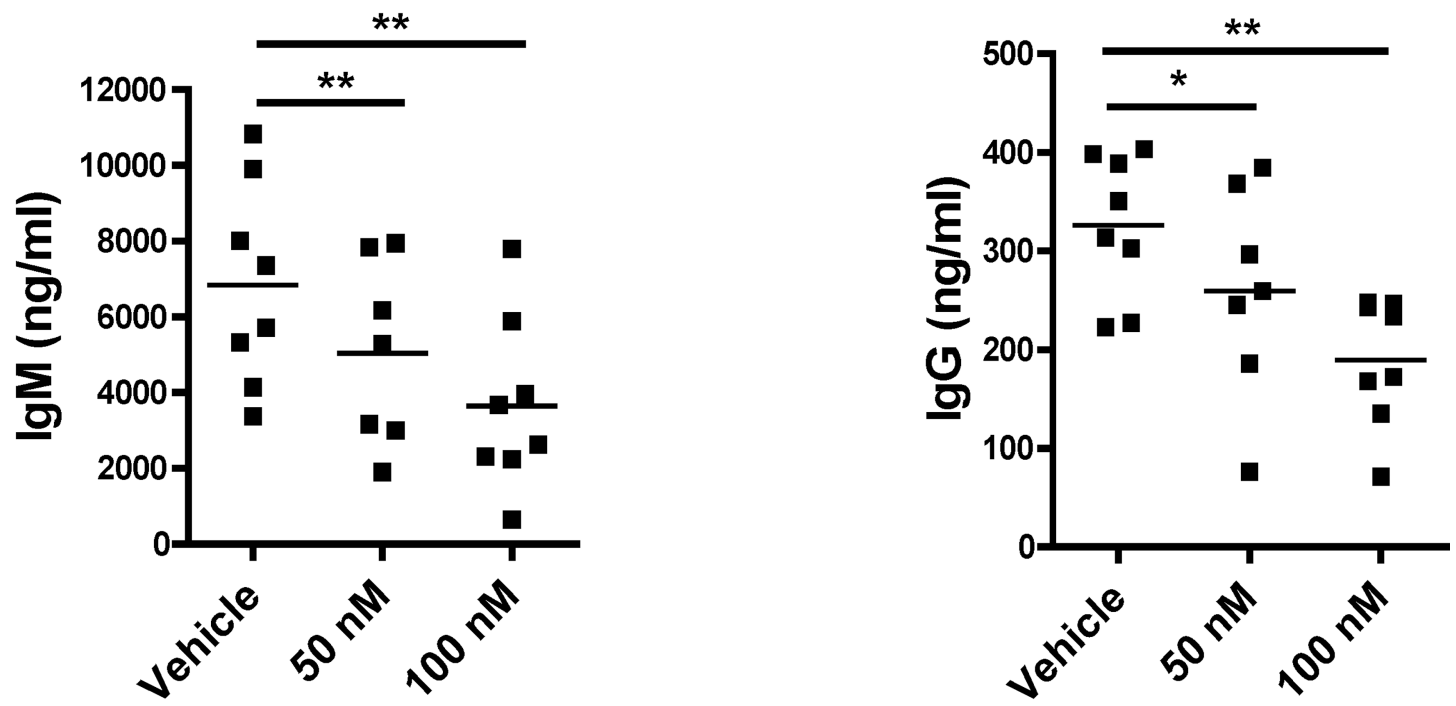

C)

\section{D)}
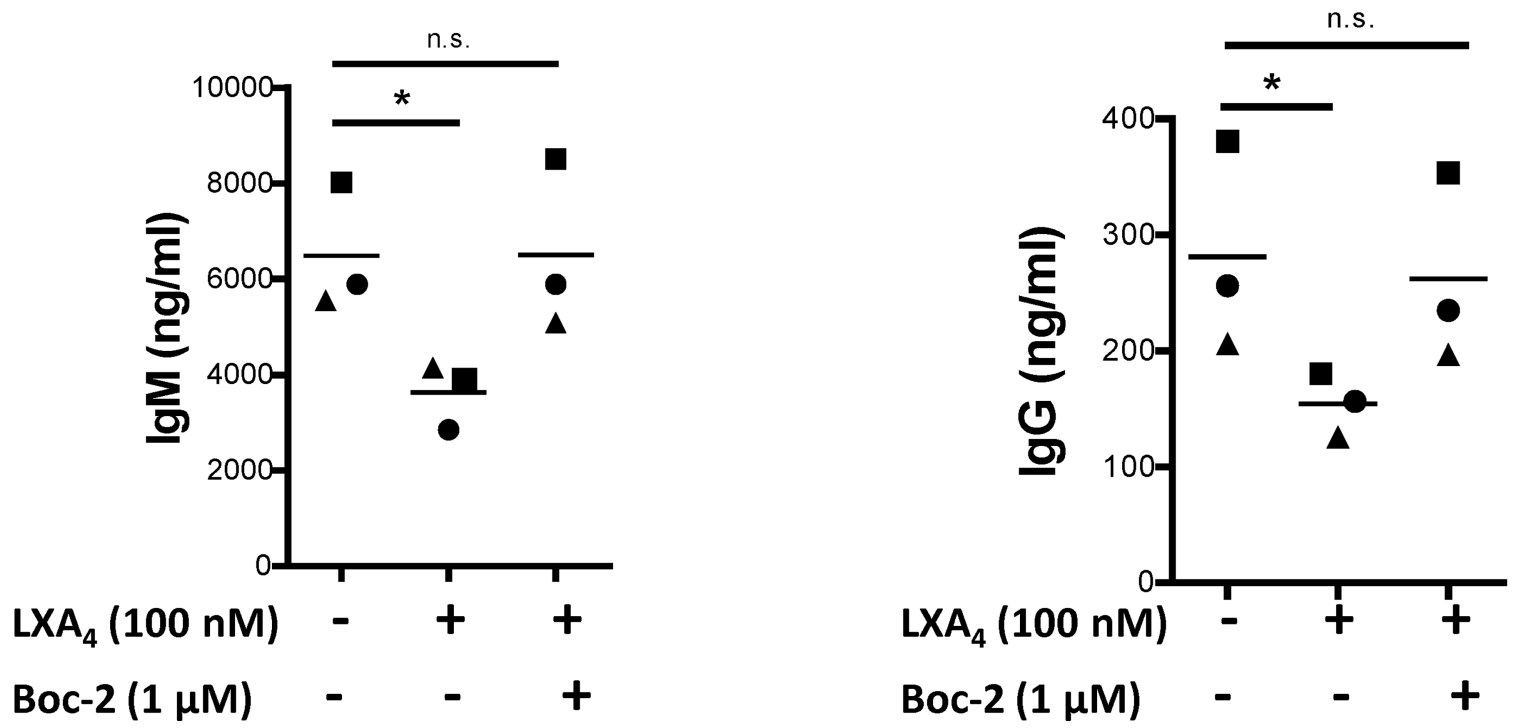

Figure 2. $\mathrm{LXA}_{4}$ reduces IgM and IgG production on human B cells via ALX/FPR2 signaling Purified B cells from healthy donors were pretreated with $\mathrm{LXA}_{4}$, followed by stimulation with CpG ODN 2395 plus anti-IgM. Cells were cultured for 6 days at which time supernatants were collected. A) IgM and B) IgG antibody levels were measured by ELISA $(\mathrm{n}=8)$. C-D) Isolated B cells were pretreated with the ALX/FPR2 antagonist Boc-2 (1 $\mu \mathrm{M})$. Cells were then treated with $\mathrm{LXA}_{4}$, followed by activation with CpG ODN 2395 plus antiIgM. Supernatants were collected at day 6 of culture, C) IgM and D) IgG production were measured by ELISA $(n=3)$. Statistical analysis done using one-way ANOVA with a Tukey's post test (*p $₫ .05, * * \mathrm{p} \unlhd 0.01$, n.s. not significant). 
A)

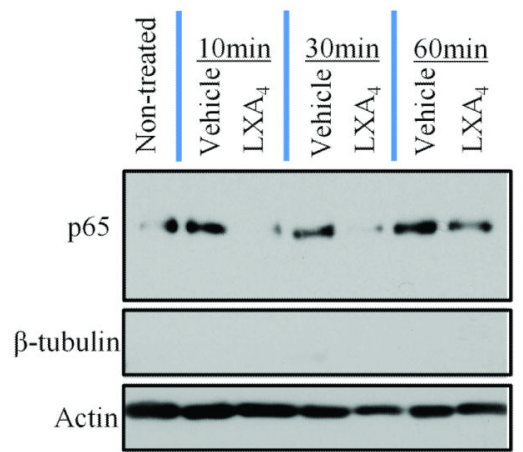

B)

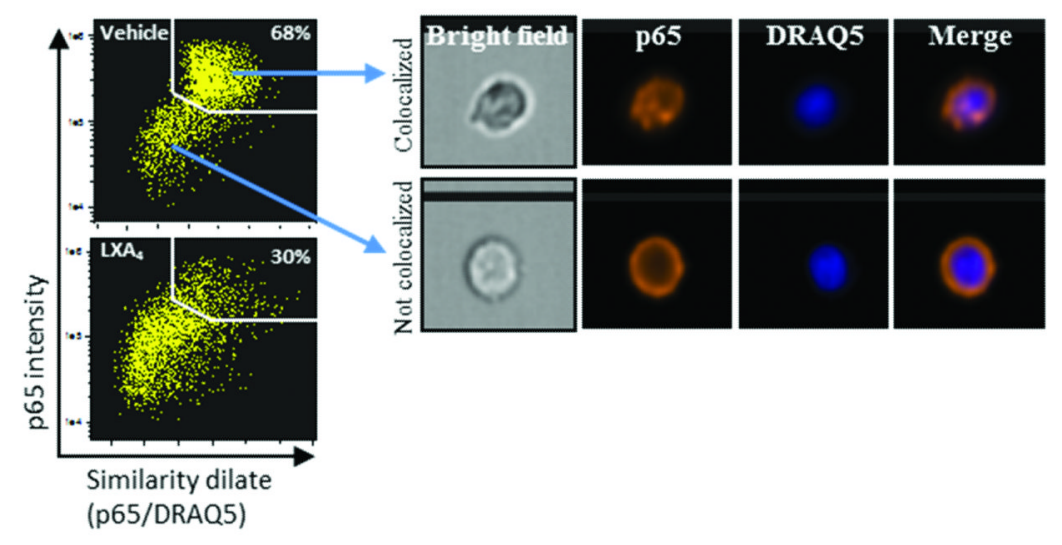

C)

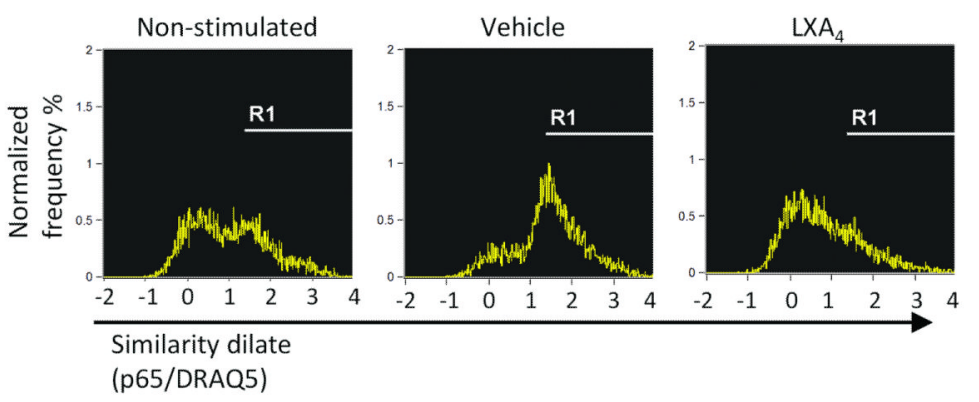

D)

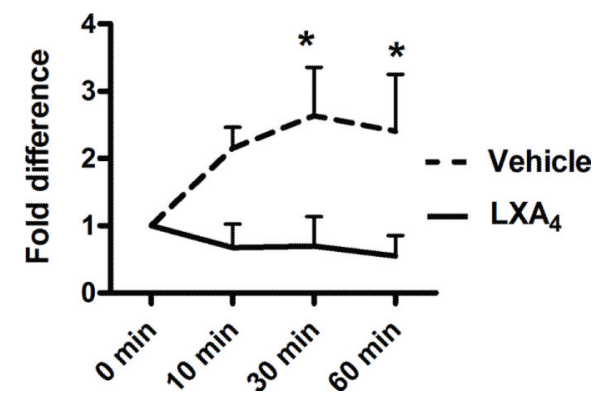

Figure 3. $\mathrm{LXA}_{4}$ signaling decreases NF- $\mathrm{kB}$ translocation to the nucleus

$\mathrm{CD} 19^{+} \mathrm{B}$ cells were treated with $\mathrm{LXA}_{4}$ or vehicle control and stimulated with CpG ODN 2395 plus anti-IgM, cells were then harvested and analyzed for NF- $\kappa B$ p65 translocation to the nucleus $(\mathrm{n}=3)$. A) Nuclear protein extracts were purified and analyzed by Western blot, $\beta$-tubulin and total actin were used as a nuclear purity control and loading control respectively. B) B cells were fixed, permeabilized and stained with the nuclear dye DRAQ5 (blue), anti-p65 (orange) and analyzed by ImageStream. Left panel shows representative dot plots of p65/DRAQ5 nuclear colocalization. Right panel shows representative images from single cells from either p65/DRAQ5 colocalized or non-colocalized populations. C) Representative histogram of p65/DRAQ5 colocalization (R1 represents colocalization positive gate). D) Quantification of p65 nuclear translocation normalized to freshly isolated B cells. Data were analyzed by two-way ANOVA with a Bonferroni post test (*p $₫$ \.05). 
A)

Freshly isolated

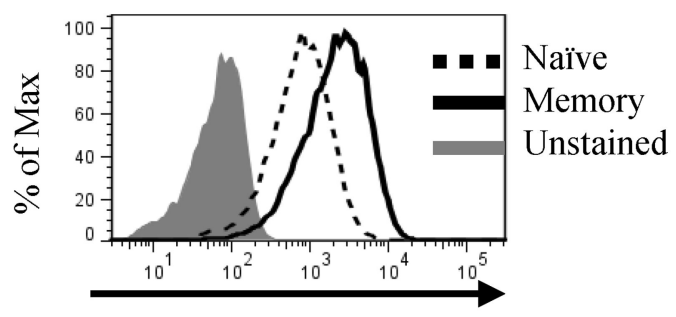

ALX/FPR2

B)
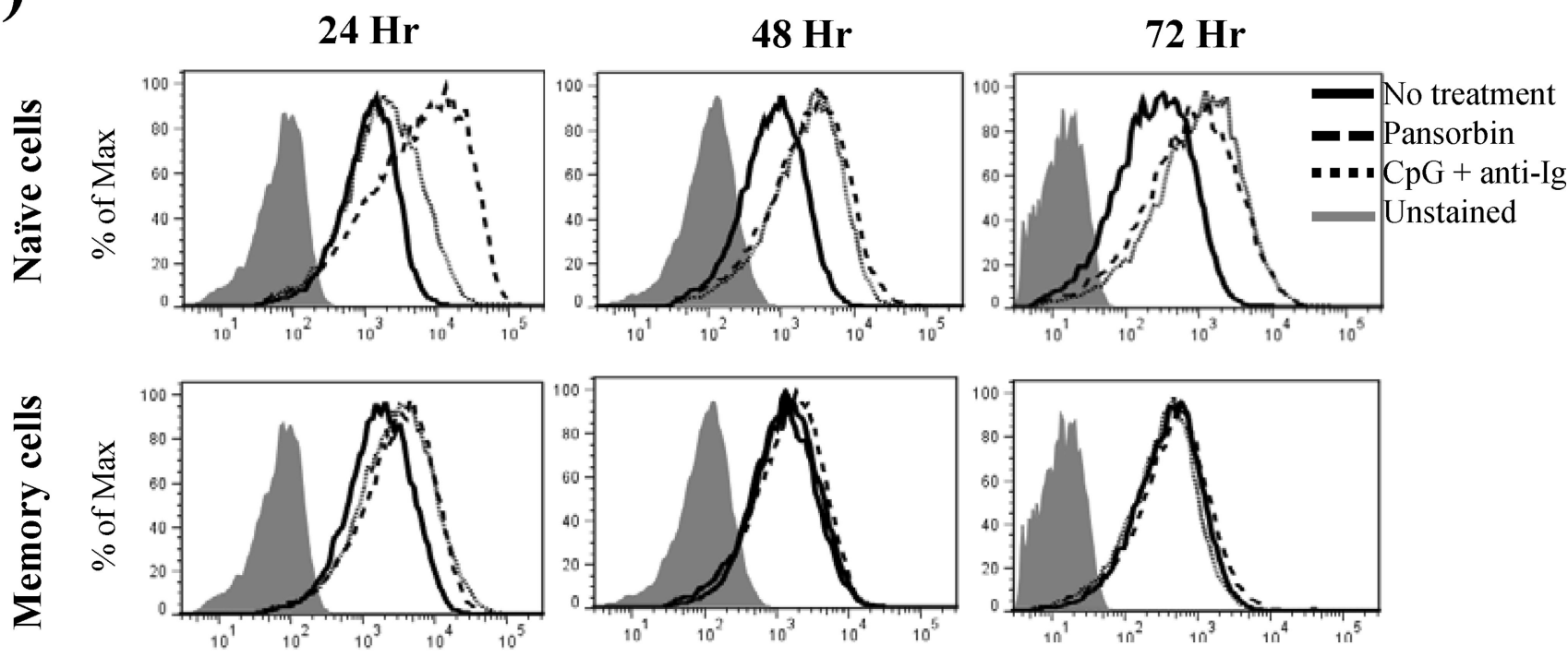

ALX/FPR2

Figure 4. ALX/FPR2 is differentially expressed in naïve and memory $B$ cells Purified B cells were surface stained and either FACS sorted or analyzed by flow cytometry $(n=3)$. A) Representative histograms of ALX/FPR2 expression on naïve (CD19+ CD27 IgD) and memory $\left(\mathrm{CD} 19^{+} \mathrm{CD} 27^{+} \mathrm{IgD}\right) \mathrm{B}$ cells, all cells were gated on live lymphocyte gate. B) B cells were stained and FACS sorted into naïve B cells $\left(\mathrm{CD} 19^{+} \mathrm{CD} 27\right)$ and memory B cells $\left(\mathrm{CD} 19^{+} \mathrm{CD} 27^{+}\right)$fractions. Naïve and memory B cells were stimulated with CpG ODN 2395 plus anti-Ig, pansorbin, or left un-stimulated for up 72 hours. At each time point cells were fixed and stained for ALX/FPR and analyzed by flow cytometry. Representative histograms of one donor are shown. 
A)

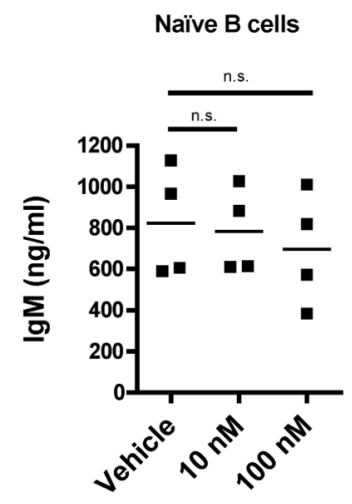

E)

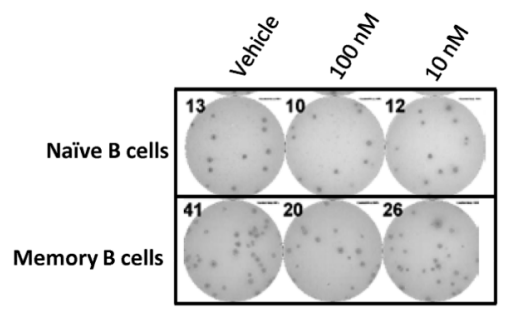

B)

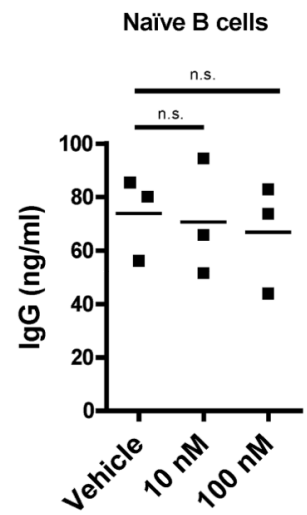

C)

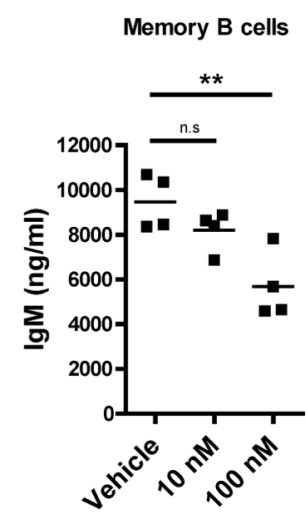

F)

Naïve B cells

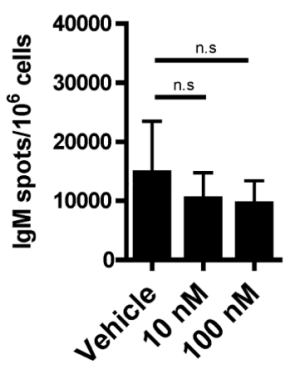

H)

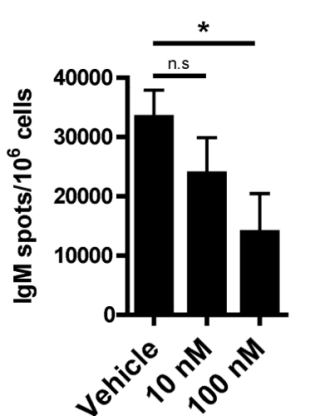

D)

Memory B cells

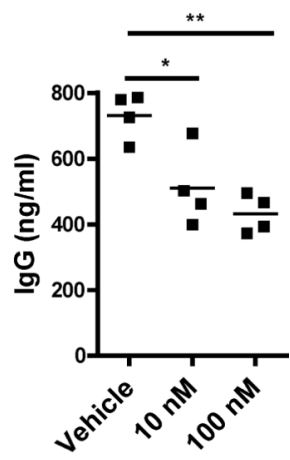

G)

Naïve B cells

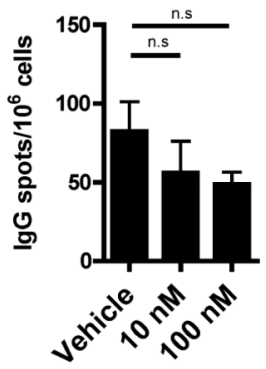

I)

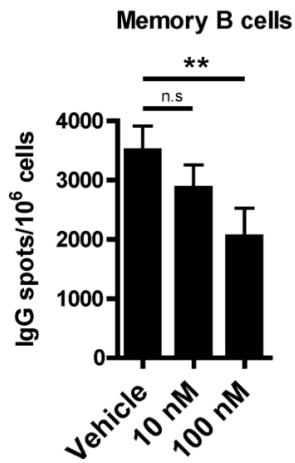

Figure 5. $\mathrm{LXA}_{4}$ decreases antibody production by memory $B$ cells but not naïve $B$ cells $\mathrm{CD} 19^{+} \mathrm{B}$ cells were stained and sorted into naïve B cells $\left(\mathrm{CD} 19^{+} \mathrm{CD} 27\right)$ and memory B cells $\left(\mathrm{CD} 19^{+} \mathrm{CD} 27^{+}\right)$. Naiive and memory cells were pretreated with $\mathrm{LXA}_{4}$ and stimulated with CpG ODN 2395 plus anti-Ig $(n=4)$. A-D) After 6 days of culture, supernatants were collected. Naïve B cell (A) IgM and (B) IgG as well as memory B cell (C) IgM and (D) IgG levels measured by ELISA. E-I) Antibody-secreting cells were counted by ELISpot. E) Representative images of IgM secreting cells in naïve and memory B cell cultures. F-I) Quantification of IgM and IgG antibody-secreting cells in $(\mathrm{F}-\mathrm{G})$ naïve and $(\mathrm{H}-\mathrm{I})$ memory B cell cultures. Results expressed as mean \pm SEM and analyzed using a one-way ANOVA with a Tukey's post test (*p $₫ 0.05$, **p $₫ 0.01$, n.s. not significant). 
A)

C)

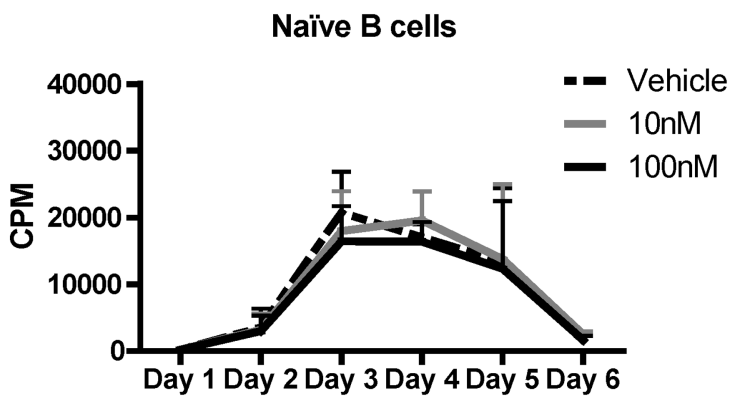

Naïve B cells

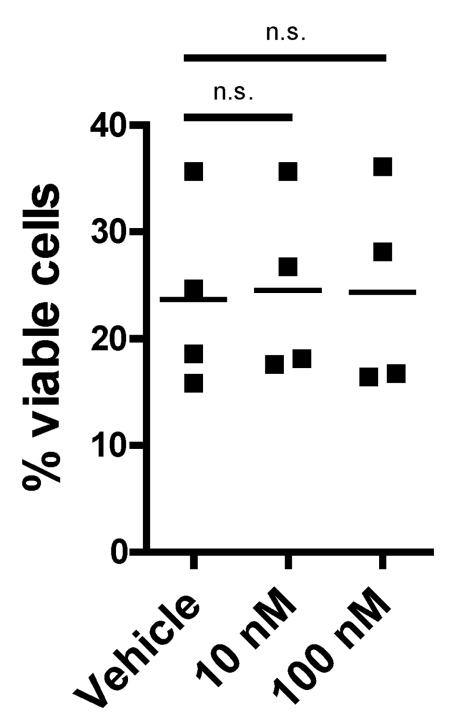

B)

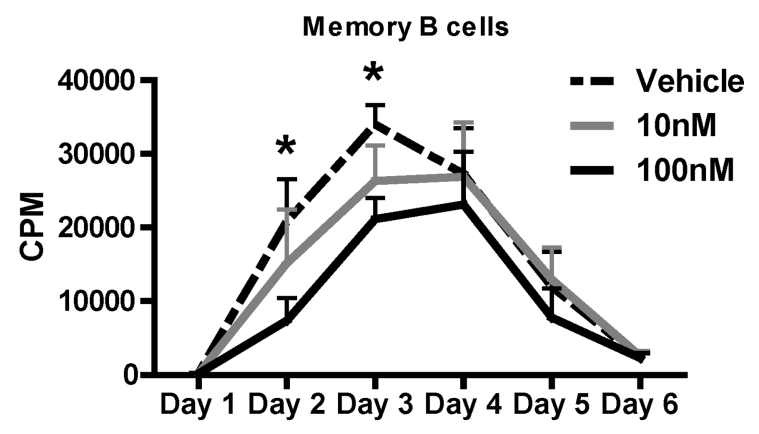

D)

Memory B cells

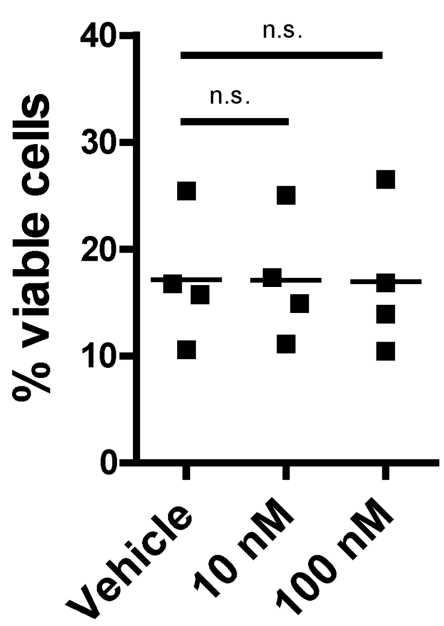

Figure 6. $\mathrm{LXA}_{4}$ decreases proliferation of memory $B$ cells but not naïve $B$ cells Naïve $\left(\mathrm{CD} 19^{+} \mathrm{CD} 27\right)$ and memory $\left(\mathrm{CD} 19^{+} \mathrm{CD} 27^{+}\right) \mathrm{B}$ cells were sorted, pretreated with $\mathrm{LXA}_{4}$ and activated with CpG ODN 2395 plus anti-Ig $(\mathrm{n}=4)$. A-B) Naïve and memory B cell proliferation was measured by $\left[{ }^{3} \mathrm{H}\right]$ thymidine incorporation assay, presented as counts per minute (cpm). C-D) Naïve and memory B cell viability was measured at day 6 using 7AAD exclusion dye and analyzed by flow cytometry. Proliferation data were analyzed by two-way ANOVA with a Bonferroni posttest. Cell death results were analyzed by one-way ANOVA with a Tukey's post test (*p $₫$.05, n.s. not significant). Results expressed as mean \pm SEM. 
A)

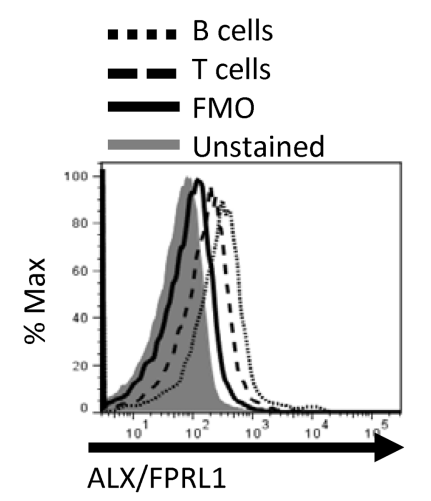

C)

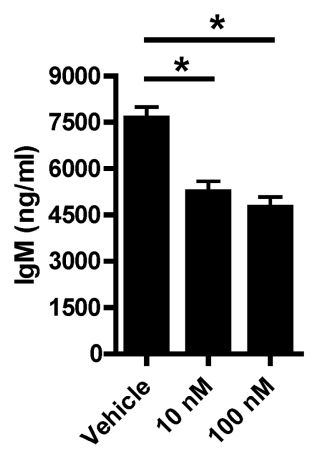

E)

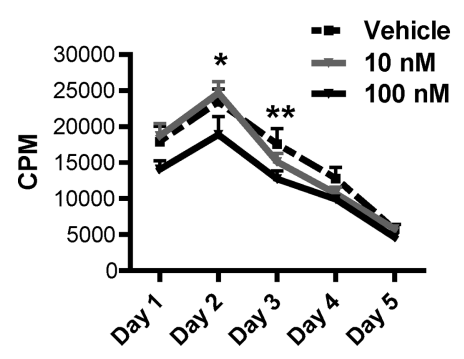

B)

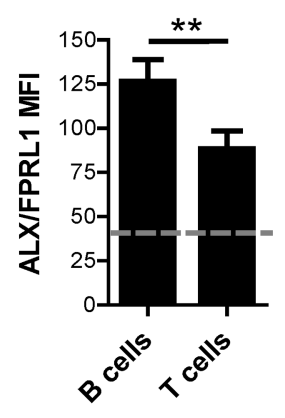

D)

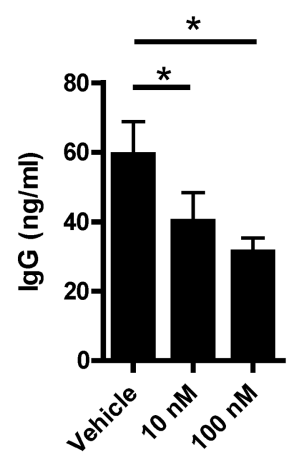

F)

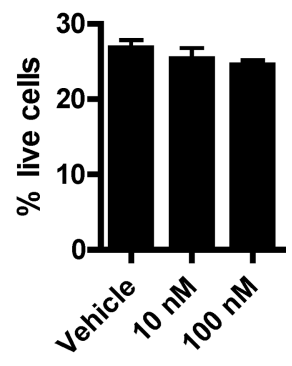

Figure 7. $\mathrm{LXA}_{4}$ decreases mouse $\mathrm{B}$ cell antibody production and proliferation in vitro Mouse splenocytes were stained for flow cytometry analysis ( $n=3)$. A) Representative histogram of ALX/FPRL1 expression on B cells (CD19+ B220+) and T cells $\left(\mathrm{CD}^{+} \mathrm{B} 220\right)$. B) Quantification of ALX/FPRL-1 expression shown as MFI (gray dotted line represent background signal). C-D) Splenocytes were treated with $\mathrm{LXA}_{4}$ or vehicle control, followed by LPS stimulation. After 6 days of culture C) $\operatorname{IgM}$ and D) IgG antibody production was measured in the supernatants $(\mathrm{n}=7)$. E) Proliferation was measured by $\left[{ }^{3} \mathrm{H}\right]$ thymidine incorporation assay over 5 days and presented as counts per minute $(\mathrm{cpm})(\mathrm{n}=5) . \mathrm{F})$ Quantification of live cells measured by 7-AAD exclusion at day 5 of treatment $(n=5)$. Results expressed as mean \pm SEM. ALX/FPRL1 MFI results were analyzed using a paired 
Student t-test. Antibody production and cell viability results were analyzed using one-way ANOVA with a Tukey's post test. Proliferation results were analyzed by two-way ANOVA with a Bonferroni post test (*p $\unlhd .05, * * \mathrm{p} \unlhd(0.01, * * * \mathrm{p} \unlhd(001)$. 
A)
B)

\section{Primary}
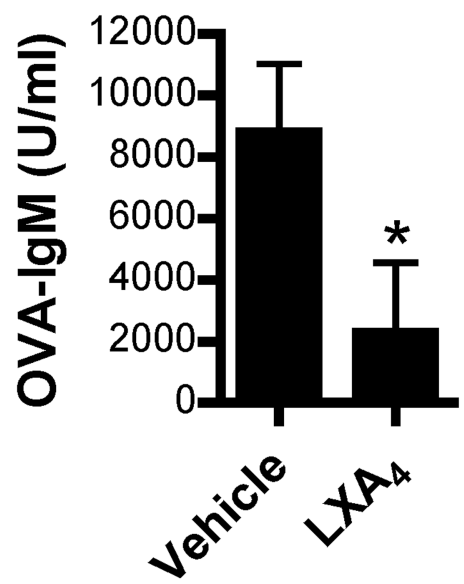

D)

\section{Secondary}

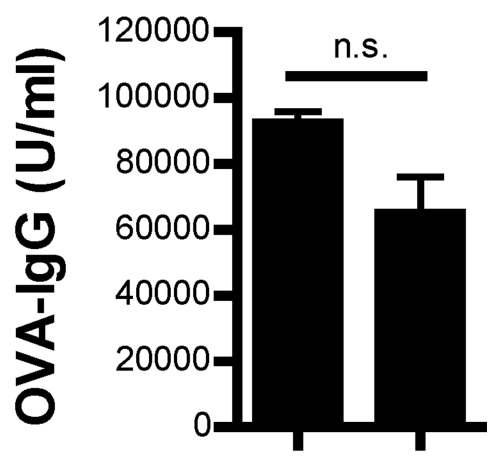

Figure 8. $\mathrm{LXA}_{4}$ decreases antigen-specific antibody production in vivo C57BL/6J mice were immunized with both OVA and vehicle control or $\mathrm{LXA}_{4}(\mathrm{n}=6)$. Two weeks after injections mice were bled and sera were isolate and use for OVA-specific A) IgM and B) IgG ELISA. Ten weeks after initial immunization mice were rechallenged with OVA, bled 2 weeks after secondary immunization and sera were use for OVA-specific C) IgM and D) IgG ELISA. Results expressed as mean \pm SEM. Data were analyzed using an unpaired t-test (*p $₫ .05$, n.s. not significant). 